\title{
Mudanças na pauta das exportações agrícolas brasileiras
}

\author{
Maria Auxiliadora de Carvalho \\ César Roberto Leite da Silva²
}

Resumo: O trabalho visa contribuir para o debate sobre desindustrialização no Brasil, atribuída à apreciação cambial que, para vários autores, decorre do aumento das exportações agrícolas. Do emprego do método constant market share sobre informações de comércio exterior da FAO, para o período 1991-2003, chegou-se à conclusão que a exportação agrícola brasileira cresceu mais que o potencial, resultado de aumento expressivo da competitividade. Depois da mudança cambial, em 1999, parte da competitividade foi neutralizada pelo aumento da participação na pauta de produtos com demanda mundial em declínio. Da decomposição do valor exportado prevaleceu o efeito do aumento da quantidade, fato mais evidente depois da mudança cambial, porque o efeito preço foi negativo. Mesmo descontando o efeito da depreciação real do câmbio, a mudança nos preços internacionais foi desfavorável à agricultura brasileira. $\mathrm{O}$ efeito flexibilidade da pauta, negativo em todo o período, indica grande participação de produtos em desacordo com a lei geral da oferta, fato mais grave no período recente, quando a maior parte dos produtos com aumento do volume exportado estava com preço em baixa no mercado internacional. O declínio da exportação de

${ }^{1}$ Doutora em Economia de Empresas - EAESP-FGV. Pesquisadora do IEA-SAA. macarvalho@iea.sp.gov.br

${ }^{2}$ Doutor em Teoria Econômica - FEA-USP. Pesquisador do IEA-SAA e Prof. Titular da PUC-SP. crlsilva@iea.sp.gov.br 
manufaturados e o maior crescimento do comércio de produtos básicos indicam tendência à desindustrialização da agricultura.

Palavras-chave: exportação agrícola, desindustrialização, constant market share

\title{
Classificação JEL: F31
}

\begin{abstract}
This paper aims to contribute to the Brazilian deindustrialization debate, attributed to exchange appreciation that, for several authors, is the agricultural export increase effect. Constant market share method applied on FAO export data, for the 1991 to 2003 period, indicates that Brazilian agricultural export increased more than the potential rate, due to expressive competitiveness gains. After the exchange regime change, in 1999, the competitiveness increase was partly neutralized by growth share of products whose world demand was in decline. Exports value decomposition showed that the volume effect predominates, fact more evident after the flotation exchange adoption, when the price effect was negative. Even discounting the real exchange depreciation effect, the international prices change was unfavourable to the Brazilian agriculture. The flexibility effect negative sign during all the period indicates great participation of products in disagreement with the offer law, fact worsened recently, when most of the products whose exports increased in volume had falling prices in the international market. The manufactured export decline and the largest basic products trade growth indicated a tendency to agribusiness deindustrialization.
\end{abstract}

Keywords: agricultural export, deindustrialization, constant market share

\section{JEL classification: F31}

\section{Introdução}

A expressão "doença holandesa” foi cunhada para expressar a perda relativa de competitividade da indústria holandesa devida à apreciação do florim que se seguiu à descoberta e exploração de grandes jazidas do 
gás natural na década de 1960. A mudança dos preços relativos levou a Holanda a passar por uma etapa de desindustrialização, processo também designado maldição dos recursos naturais.

Na década de 1990 essa doença “... também se espalhou para alguns países latino-americanos; mas a questão central neste caso é que ela não foi originada pela descoberta de recursos naturais ... mas sim principalmente devido a uma drástica mudança no seu regime de política econômica. Basicamente, ela resultou de um processo drástico de liberalização comercial e financeira no contexto de um processo radical de mudança institucional..." (PALMA, 2005, p. 20).

O autor acrescenta que o Brasil e os três países do Cone Sul (Argentina, Chile e Uruguai), que eram os países latino-americanos mais industrializados, depois de suas reformas econômicas passaram a apresentar os níveis mais altos de desindustrialização. "O fim das políticas industriais e comerciais, aliado às mudanças nos preços relativos, nas taxas de câmbio efetivas, na estrutura institucional das economias, na estrutura dos direitos de propriedade e nos incentivos de mercado em geral levaram esses países de volta à sua posição Ricardiana 'natural', isto é, aquela mais de acordo com sua dotação tradicional de recursos" (PALMA, 2005, p. 21).

Essa posição Ricardiana "natural” explica boa parte do sucesso do agronegócio brasileiro pós-liberalização comercial fazendo com que, mesmo nas fases de apreciação real da taxa de câmbio doméstica, o setor fosse capaz de gerar superávits comerciais expressivos.

Dos superávits agrícolas o Brasil evoluiu para superávits em conta corrente e ingresso de capitais suficientes para provocar a valorização da moeda local. Pela teoria econômica, num regime de câmbio flutuante espera-se que a moeda valorizada estimule importações de bens e serviços e iniba exportações, de forma que a maior demanda por moeda estrangeira deprecie a moeda local. Na prática isso não aconteceu, e o país continua apresentando superávits recordes, a despeito do câmbio valorizado.

Os ramos da atividade industrial inaptos para enfrentar a concorrência internacional com câmbio valorizado vêm perdendo participação na economia e provocando questionamentos sobre a desindustrialização do país. A busca de explicação para esses acontecimentos colocou a agricultura no centro do debate. Para muitos analistas a grandeza da compe- 
titividade agrícola é a maior causa da apreciação cambial e, conseqüentemente, da propagação da doença holandesa na economia brasileira.

Desde meados de 2005 a temática da doença holandesa, ou desindustrialização, permeou o debate econômico no Brasil. O processo está em curso e a proposta deste trabalho é somar uma pequena contribuição. Se a agricultura vem condicionando a dinâmica econômica do Brasil no período recente, inclusive com influência marcante sobre a taxa de câmbio, cabe investigar com mais apuro os determinantes de seu desempenho. Para isso foi empregado o método denominado constant market share (CMS) sobre as estatísticas de exportação agrícola do período 1991-2003.

O emprego do método foi realizado em duas etapas. A primeira para analisar a taxa de crescimento do valor das exportações e identificar a influência do crescimento do comércio mundial, da composição da pauta e da competitividade da agricultura brasileira.

A segunda etapa segmenta o valor das exportações em seus componentes preço e quantidade para conhecer a influência de cada uma dessas variáveis sobre o desempenho das exportações. Nessa etapa obtémse também o efeito flexibilidade, que reflete as mudanças ocorridas na distribuição da pauta agrícola.

\section{Rumo à Maldição dos Recursos Naturais}

Com a expressão “a década do agronegócio”, Neves (2004) exalta a competência adquirida, a tecnologia, a abundância de recursos e coloca um conjunto de desafios que o setor agrícola brasileiro ainda teria que enfrentar para permanecer na trajetória de crescimento que caracterizou os dez anos anteriores a 2004.

Gasques et al. (2004, p. 35) analisaram um conjunto de indicadores que os levou a concluir que "O agronegócio é claramente um caso de sucesso do país. Sua competitividade internacional é patente em muitas culturas; a produtividade da agropecuária avança, revelada pelo aumento da produção sem correspondente aumento da área plantada; desbrava-se a fronteira agrícola dando perspectiva às regióes do cerrado do Centro-Oeste, e alcançando a área do meio-oeste".

Esses são apenas dois exemplos que refletem o entusiasmo pelo de- 
sempenho do setor agrícola após a liberalização comercial da década de 1990. Mas o que pode ser considerado bom para o setor será também válido para o conjunto da economia? Há quem pense que a economia brasileira esteja numa trajetória de risco, por conseqüência da própria liberalização comercial que impulsionou o setor agrícola a esse desempenho tido como espetacular. Nessa interpretação, a realocação de recursos que sucedeu a abertura levou ao processo de desindustrialização das economias pouco desenvolvidas, cuja indústria ainda era incipiente e, portanto, incapaz de enfrentar a concorrência internacional.

Esse alerta levou à reabertura do debate sobre o desenvolvimento, que esteve ausente do discurso econômico durante a longa hegemonia do pensamento neoliberal. A experiência histórica mostra que o desenvolvimento econômico é um processo que leva a grandes mudanças na estrutura de emprego. Na fase inicial, devido ao aumento da produtividade na agricultura, a mão-de-obra desse setor começa a ser liberada, sendo absorvida principalmente pela indústria, o que caracteriza a fase da industrialização da economia. A participação do emprego industrial cresce até atingir determinado patamar e depois passa a cair. É a etapa de desindustrialização natural, em que o declínio da indústria é acompanhado pelo crescimento do setor terciário e implica melhoria do padrão de vida da sociedade.

As mudanças na participação de cada setor no nível de emprego estão relacionadas à correspondente participação do valor adicionado no produto nacional. A desindustrialização é prematura quando há um declínio precoce da relação entre o valor adicionado no setor manufatureiro e o Produto Nacional Bruto (PNB). Os indicadores de Shafaeddin (2005) mostram que isso aconteceu na América Latina e na África, com exceção daquelas indústrias que já tinham alcançado estágio avançado de maturidade $^{3}$. O autor acrescenta que em alguns países em desenvolvimento esse processo foi agravado pelo boom de preços de determinadas commodities, como o caso do petróleo na década de 1970 e começo da de 1990.

Maldição dos recursos naturais é outra forma de referência à doença holandesa, e recebeu este nome porque reflete um paradoxo. A riqueza

3 "It is due to the re-orientation of the production structure of the economy from import substitution strategies towards production on the basis of static comparative advantage due to trade liberalization" (SHAFAEDDIN, 2005, p. 17). 
em recursos naturais, que em princípio é uma bênção, pode inibir ou estancar o desenvolvimento da indústria, com implicações desastrosas sobre o nível de emprego. "A Holanda, depois de sua descoberta de gás e petróleo, viu-se vitimada por crescente desemprego e incapacitação da força-de-trabalho... Quando o câmbio dispara, devido a uma explosão no crescimento dos recursos naturais, os países não conseguem exportar artigos de sua indústria de transformação ou mercadorias agrícolas, e os produtores domésticos não podem competir com a enxurrada de importações" (STIGLITZ, 2004).

Bresser Pereira (2005a) considera que no Brasil atual a doença holandesa não tem tanta gravidade como na Venezuela ou Arábia Saudita porque o país não é grande exportador de petróleo. "Mas, como possui recursos naturais abundantes, que possibilitam a produção agrícola e agroindústria a custos baixos, o problema da maldição dos recursos naturais não pode ser subestimado".

A ligação entre exportações agrícolas, câmbio e desempenho da indústria não é novidade no Brasil. Todo o ciclo do café foi marcado por alternâncias entre surtos de industrialização e retrocessos associados ao desempenho do produto no comércio exterior. Novidade é empregar as expressões "maldição dos recursos naturais" e "doença holandesa" para definir esses surtos industriais do passado, como fez Bresser Pereira (2005b.).

A discussão desse problema, que se restringia ao meio acadêmico, transbordou para a mídia brasileira, a partir do segundo semestre de 2005, devido ao recrudescimento da apreciação cambial. Além de buscar explicação para a persistência dos superávits comerciais, o debate denota a preocupação com o futuro do país. Parece que aquilo que era tido como sucesso até outro dia, passou a ser visto como entrave. Ricupero (2005), por exemplo, argumenta que os superávits produzidos pelos produtos primários "criaram a falsa sensação de segurança" e que a desindustrialização se origina na política econômica.

Barros (2005) considera que nos casos antigos de doença holandesa o natural ajuste da economia fazia com que as taxas de juros caíssem abaixo das do mercado internacional. Na atualidade o componente especulativo amplifica o efeito dos superávits comerciais sobre a taxa de câmbio, criando uma armadilha nova para as nações exportadoras de 
recursos naturais. Acrescenta que o Brasil enfrenta ainda o agravante de combinar superávits comerciais com taxas de juros estratosféricas.

Pastore e Pinotti (2006) consideram que a “... valorização do real seria inevitável mesmo com taxas domésticas de juros muito mais baixas, em razão do choque externo que vem valorizando inexoravelmente o câmbio real." Para eles, o choque externo provém do aumento dos preços internacionais das commodities e das importações mundiais, fatos que elevaram as exportações brasileiras, gerando superávits e valorização da moeda.

Para o IEDI (2005), a desindustrialização é relativa e a razão dessa qualificação é que o processo foi parcial: atingiu têxteis, material elétrico e eletrônico, ramos tradicionais da indústria brasileira, enquanto aumentou a especialização da indústria brasileira em setores intensivos em recursos naturais. Conclui que “... o dinamismo industrial vem dependendo nos últimos anos de um menor número de atividades industriais. Este poderá ser considerado um sintoma de "desindustrialização relativa' no período recente" (IEDI, 2005, p. 13)".

Conclusões semelhantes às de IEDI (2005) resultaram do trabalho de Shafaeddin (2005) para quem os programas de ajuste estrutural aplicados nas economias da América Latina, tiveram como objetivo aumentar a eficiência, promover o crescimento e, à medida que indústrias ineficientes desaparecessem, seriam naturalmente substituídas pelas eficientes. Na prática, o processo de maturação de muitas indústrias foi interrompido bruscamente e a indústria que vem surgindo é centrada nos recursos naturais abundantes em cada país.

\section{Metodologia e Base Empírica}

O modelo constant market share (CMS) foi utilizado para identificar alguns fatores determinantes do valor das exportações agrícolas brasileiras. A aplicação do modelo foi feita em duas etapas.

\subsection{Análise das Mudanças nos Preços e Quantidades Exportadas}

Seja $X_{i t}$ o valor total das exportações do país $i$ em determinado período $t$ :

RER, Rio de Janeiro, vol. 46, no 01, p. 053-073, jan/mar 2008 - Impressa em abril 2008 


$$
X_{i t}=\sum_{j=1}^{n} P_{i j t} \cdot Q_{i j t}
$$

onde: $P_{i j t}=$ preço do produto $j$ exportado pelo país $i$ no período final $t$; $Q_{i j t}=$ quantidade do produto $j$ exportada pelo país $i$ no período final $t$.

No período inicial (0) o valor total das exportações é:

$$
X_{i 0}=\sum_{j=1}^{n} P_{i j 0} \cdot Q_{i j 0}
$$

O crescimento ocorrido no valor exportado entre o período inicial e final $\left(\Delta X_{i}^{0}\right)$ é:

$$
\Delta X_{i}^{O}=\sum_{j=1}^{n} P_{i j t} \cdot Q_{i j t}-\sum_{j=1}^{n} P_{i j 0} \cdot Q_{i j 0}
$$

A mudança no valor depende das alterações no preço, no volume das exportações e na flexibilidade da pauta, efeitos que podem ser estimados pela seguinte expressão:

$$
\Delta X_{i}^{O}=\left(X_{i t}^{P}-X_{i 0}\right)+\left(X_{i t}^{Q}-X_{i 0}\right)+\left\{X_{i t}-\left[\left(X_{i t}^{P}-X_{i 0}\right)+\left(X_{i t}^{Q}-X_{i 0}\right)\right]-X_{i 0}\right\}(4)
$$

onde: $\quad X_{i t}^{P}=\sum_{i=1}^{n} P_{i j t} \cdot Q_{i j 0}$;

$$
X_{i t}^{Q}=\sum_{j=1}^{n} P_{i j 0} \cdot Q_{i j t}
$$

$\left(X_{i t}^{P}-X_{i 0}\right)$ representa o efeito preço;

$\left(X_{i t}^{Q}-X_{i 0}\right)$ representa o efeito quantidade; e

$\left\{X_{i t}-\left[\left(X_{i t}^{P}-X_{i 0}\right)+\left(X_{i t}^{Q}-X_{i 0}\right)\right]-X_{i o}\right\}$ representa o efeito flexibilidade da pauta.

O efeito flexibilidade da pauta é obtido por resíduo e, quando apresenta sinal positivo significa que predominam produtos em que o preço varia na mesma direção da quantidade. Um sinal negativo indica predomínio de produtos cuja quantidade exportada cresce a despeito de queda no preço e vice-versa. 


\subsection{Análise da Competitividade ${ }^{4}$}

Nesta etapa a idéia é decompor a diferença entre o crescimento ocorrido nas exportações do país $i$ e o crescimento potencial, entendido como o crescimento que teria ocorrido se as exportações de $i$ tivessem o mesmo crescimento das importações mundiais.

Seja $m$ a taxa de crescimento das importações mundiais entre o período inicial e final, essa pode ser representada como na Equação (5):

$$
m=\frac{M_{w j t}}{M_{w j o}}-1
$$

cial 0; e

onde: $M_{w 0}=\sum_{j=1}^{n} M_{w j 0}$ são as importações mundiais no período ini-

$$
M_{w t}=\sum_{j=1}^{n} M_{w j t} \text { são as importações mundiais no período final } t \text {. }
$$

Dessa forma, o crescimento potencial das exportações de $i\left(\Delta X_{i}^{P}\right)$ é dado por:

$$
\Delta X_{i}^{P}=m \sum_{j=1}^{n} X_{i j 0}
$$

Se $\Delta X_{i}^{O}=\Delta X_{i}^{P}$, infere-se que o país manteve seu market-share no mercado internacional. Se $\Delta X_{i}^{O} \neq \Delta X_{i}^{P}$, a diferença pode ser decomposta como:

$$
\Delta X_{i}^{O}-\Delta X_{i}^{P}=\sum_{j=1}^{n}\left(m_{j}-m\right) X_{i j 0}+\sum_{j=1}^{n}\left(X_{i j t}-X_{i j 0}-m_{j} X_{i j 0}\right)
$$

onde $m_{j}=$ taxa de crescimento das importações mundiais do produto $j$;

$\sum_{j=1}^{n}\left(m_{j}-m\right) X_{i j 0}$ representa o efeito composição da pauta de exportação;

e

$\sum_{j=1}^{n}\left(X_{i j t}-X_{i j 0}-m_{j} X_{i j 0}\right)$ representa o efeito competitividade.

${ }^{4}$ Decomposição com base em PUGA. et al. (2005) . 
O crescimento das exportações acima do crescimento potencial pode ser devido à concentração das exportações em produtos cuja demanda mundial esteja em expansão (efeito positivo da composição da pauta de exportação) e/ou ao aumento do market-share do país no mercado internacional (efeito positivo da competitividade).

\subsection{Base Empírica}

A análise foi feita sobre o valor das exportações agrícolas brasileiras, tendo a FAO como fonte de informações para o período 1991-2003 (FAOSTAT, 2005). O modelo CMS foi aplicado sobre as médias dos seguintes triênios: 1991-93, 1996-98 e 2001-03. Foram considerados todos os produtos pertencentes à pauta agrícola da FAO, para os quais o Brasil registrou alguma exportação nos triênios considerados. A base de dados da FAO registra 617 produtos agrícolas e o Brasil teve exportação de 390 deles.

\section{Discussão dos Resultados}

O trabalho analisa o período 1991-2003, que sucedeu à liberalização comercial da economia brasileira, subdividido em duas etapas, tendo a mudança do regime cambial como referência. O confronto das médias dos triênios 1991-93 e 1996-98 visa analisar o desempenho das exportações agrícolas antes da mudança cambial. A comparação de 1996-98 e 2001-2003 investiga o período posterior a essa mudança.

Para manter a participação no comércio agrícola mundial inalterada, as exportações brasileiras precisariam crescer a uma taxa de 3,0\% ao ano entre o primeiro e último triênios da série analisada (crescimento potencial). Na realidade, o crescimento ocorrido foi bem maior que isso ( $7,2 \%$ ao ano) e a diferença pode ser explicada por mudanças na composição da pauta ou na competitividade do país no mercado internacional. Observe-se que medida em dólar, a diferença totaliza cerca de US\$ 6,0 bilhões, mas o efeito composição da pauta mostrou-se relativamente irrisório (US\$ 261 milhões). Isso significa que o grande sucesso da agricultura brasileira no mercado internacional foi devido basicamente à melhoria da competitividade: os restantes US $\$ 5,7$ bilhões dos US\$ 
6,0 bilhões de diferença entre o crescimento ocorrido nas exportações agrícolas e o crescimento potencial (Tabela 1).

Tabela 1. Fontes de Crescimento das Exportações Agrícolas, Brasil, 1991 a 2003

\begin{tabular}{|c|c|c|c|c|c|c|}
\hline \multirow{2}{*}{ Item } & \multicolumn{2}{|c|}{$1991-93$ a $1996-98$} & \multicolumn{2}{|c|}{$1996-98$ a 2001-03 } & \multicolumn{2}{|c|}{$1991-93$ а 2001-03 } \\
\hline & U\$ milhão & $\%$ a.a. & U\$ milhão & $\%$ a.a. & U\$ milhão \% & a.a. \\
\hline Crescimento ocorrido & 6.253 & 11,2 & 2.766 & 3,4 & 9.019 & 7,2 \\
\hline Crescimento potencial & 2.929 & 5,8 & 182 & 0,2 & 3.071 & 3,0 \\
\hline Diferença & 3.324 & 5,4 & 2.584 & 3,2 & 5.947 & 4,2 \\
\hline - Efeito composição da pauta & 1.293 & 2,1 & -1.297 & $-1,6$ & 261 & 0,2 \\
\hline - Efeito competitividade & 2.031 & 3,3 & 3.881 & 4,8 & 5.687 & 4,0 \\
\hline
\end{tabular}

A análise por sub-período mostra maior ritmo de crescimento das exportações agrícolas antes da mudança cambial, quando a taxa de câmbio se encontrava bastante valorizada. Nesse período, as exportações brasileiras cresceram $11,2 \%$ ao ano, enquanto as importações mundiais desses produtos cresciam $5,8 \%$ ao ano. Em termos monetários, o crescimento ocorrido (US\$ 6.253 milhões) foi mais que o dobro do potencial (US\$2.929 milhões).

Parte da diferença calculada (US\$ 1.293 milhões) resultou de mudanças na composição da pauta de exportação brasileira, com aumento da participação de produtos cuja demanda mundial estava em crescimento. A outra parte (US\$2.031 milhões) resultou de ganhos de competitividade do país no cenário internacional. $\mathrm{O}$ aumento de competitividade se deu à taxa média anual de $3,3 \%$ e a melhoria da composição da pauta de exportação à taxa de $2,1 \%$ a.a., efeitos que,somados, resultam nos $5,4 \%$ ao ano, diferença entre o crescimento ocorrido e o potencial.

Entre os triênios 1996-98 e 2001-03 o ritmo de crescimento das exportações agrícolas brasileiras arrefeceu, passando para 3,4\% ao ano. Por um lado, esse desempenho pode ser entendido como um grande sucesso, dado que a taxa anual de crescimento das importações agrícolas mundiais foi de apenas $0,2 \%$ ao ano. Dessa forma, para manter a participação no mercado agrícola mundial, bastaria aumentar as exportações em US\$ 182 milhões, mas o Brasil registrou crescimento de US $\$ 2.766$ bilhões, 
com aumento de competitividade à taxa de 4,8\% ao ano. Por outro lado, o sucesso é relativo uma vez que a composição da pauta apresentou efeito negativo (-1,6\% ao ano), o que significa aumentar o market-share do país em produtos com demanda mundial cadente. Essa é a chamada situação de vulnerabilidade, no dizer de Fajnzylber (1991).

O modelo CMS mostrou que a agricultura brasileira aumentou a competitividade a partir da década de 1990. Por que o Brasil tornou-se mais competitivo? O próprio modelo CMS também pode contribuir para responder a essa questão, segmentando a variação no valor das exportações nos efeitos: preço, quantidade e flexibilidade da pauta.

Os resultados mostram que antes da mudança do regime cambial, quando a taxa de câmbio encontrava-se significativamente apreciada, os $11,2 \%$ ao ano de crescimento das exportações agrícolas foram resultado dos efeitos de alta dos preços $(6,9 \%$ ao ano), de aumento da quantidade exportada $(6,0 \%$ ao ano), descontado o efeito flexibilidade da pauta $(-1,8 \%$ ao ano). Esse efeito é obtido por diferença e, quando negativo, indica a concentração em produtos cujos preços variaram em direção inversa às quantidades (Tabela 2).

Tabela 2. Componentes da Variação Média Anual do Valor das Exportações Agrícolas Brasileiras, medido em dólar; Período: 1991 a 2003 (em porcentagem)

\begin{tabular}{cccccc}
\hline Inicial & Final & Preço & Quantidade & Flexibilidade & Total \\
\hline $1991-93$ & $1996-98$ & 6,9 & 6,0 & $-1,8$ & 11,2 \\
$1996-98$ & $2001-03$ & $-7,3$ & 12,2 & $-1,5$ & 3,4 \\
$1991-93$ & $2001-03$ & $-0,5$ & 9,0 & $-1,3$ & 7,2 \\
\hline
\end{tabular}

Fonte de dados básicos: FAOSTAT.

A observação direta dos números mostra que nesse período, dos 390 produtos constantes na pauta agrícola brasileira, 49 tiveram aumento da quantidade e redução de preços, sendo que representaram apenas 1,4\% do valor das exportações agrícolas de 1996-98. Na situação inversa foram encontrados 104 produtos, com participação de 25,3\% no valor exportado. De onde se conclui que, na primeira parte da década de 1990, o efeito flexibilidade da pauta negativo mais se deveu aos produtos que tiveram redução da quantidade exportada, embora os preços estivessem em alta (Tabela 3). 
Tabela 3. Número e Proporção do Valor das Exportações Agrícolas Brasileiras dos Produtos cuja Quantidade Exportada Variou em Direção Inversa dos Preços. Período: 1991 a 2003

\begin{tabular}{|c|c|c|c|c|c|c|c|}
\hline \multirow{2}{*}{ Informação } & \multirow{2}{*}{ Direção } & \multicolumn{2}{|c|}{$1991-93$ a $1996-98$} & \multicolumn{2}{|c|}{$1996-98$ a $2001-03$} & \multicolumn{2}{|c|}{$1991-93$ a 2001-03 } \\
\hline & & Número & $\%$ & Número & $\%$ & Número & $\%$ \\
\hline $\begin{array}{l}\text { Preço } \\
\text { Quantidade }\end{array}$ & $\begin{array}{l}\text { Diminui } \\
\text { Aumenta }\end{array}$ & 49 & 1,4 & 172 & 88,1 & 124 & 82,9 \\
\hline $\begin{array}{l}\text { Preço } \\
\text { Quantidade }\end{array}$ & $\begin{array}{l}\text { Aumenta } \\
\text { Diminui }\end{array}$ & 104 & 25,3 & 29 & 0,3 & 48 & 1,0 \\
\hline
\end{tabular}

Fonte de dados básicos: FAOSTAT.

Entre os triênios 1996-98 e 2001-03 a situação foi inversa. Com preço em alta e redução da quantidade exportada, foram encontrados apenas 29 produtos que contribuíram com $0,3 \%$ do valor exportado em 2001-03. Significa que os 172 produtos com preços em baixa e volume exportado em expansão, que representavam $88,1 \%$ do valor exportado no triênio final, foram determinantes do efeito flexibilidade da pauta negativo ( $-1,5 \%$ ao ano).

São eles também os maiores responsáveis pelos efeitos preço e quantidade. $\mathrm{O}$ aumento do valor exportado, à taxa média anual de 3,4\% no período, decorre do predomínio do efeito quantidade (12,2\% ao ano), uma vez que os outros efeitos apresentaram sinal negativo. Note-se que a contribuição do preço foi bastante expressiva, com redução à taxa média anual de 7,3\%.

A análise de todo o período mostra que na composição do crescimento ocorrido na exportação $(7,2 \%$ ao ano) o efeito quantidade $(9,0 \%$ ao ano) prevaleceu, enquanto o efeito preço foi bem reduzido e negativo $(-0,5 \%$ ao ano). Como apenas 48 produtos tiveram alta de preço e queda na quantidade o efeito flexibilidade da pauta desfavorável $(-1,3 \%$ ao ano), decorre dos 124 produtos que, a despeito da redução nos preços, o Brasil aumentou suas exportações: $82,9 \%$ do valor exportado procedem de produtos nessa situação.

A subdivisão da pauta agrícola nos grupamentos básico, semimanufaturado e manufaturado mostra que todos apresentaram efeito flexibilidade 
negativo entre os triênios analisados ${ }^{5}$. Predominaram, portanto, em todos os casos, produtos cuja quantidade exportada variou em sentido inverso ao do preço. A diferença é que, entre 1991-93 e 1996-98, quando os preços estavam em alta, o menor efeito flexibilidade coube aos produtos básicos, $-0,9 \%$ ao ano, enquanto os outros dois grupos tiveram variação de cerca de $-3 \%$ ao ano. No período recente de preços em baixa, houve inversão do ritmo de crescimento, sendo que os básicos passaram a apresentar o maior efeito flexibilidade: $-1,6 \%$ ao ano, contra $-0,7 \%$ ao ano dos produtos manufaturados. Isso significa que os produtos básicos se tornaram os maiores responsáveis pelo aumento da quantidade exportada de produtos com preços em baixa no mercado internacional (Tabela 4).

Tabela 4. Componentes da Variação Anual do Valor das Exportações Agrícolas Brasileiras por Tipo de Produto. Período: 1991a 2003 (') (em porcentagem)

\begin{tabular}{lcccc}
\hline Produto & Preço & Quantidade & Flexibilidade & Total \\
\hline Básico & \multicolumn{4}{c}{$1991-93$ a $1996-98$} \\
Semimanufaturado & 4,2 & 4,5 & $-0,9$ & 10,8 \\
Manufaturado & 7,0 & 13,4 & $-2,8$ & 13,4 \\
& & 7,1 & $-3,0$ & 11,1 \\
Básico & $-8,1$ & $1996-98$ a $2001-03$ & \\
Semimanufaturado & $-6,9$ & 10,0 & $-1,6$ & 5,3 \\
Manufaturado & $-5,8$ & 6,2 & $-1,5$ & 1,5 \\
& & $1991-93$ a $2001-03$ & $-0,3$ \\
Básico & $-1,6$ & 9,7 & $-0,1$ & 8,0 \\
Semimanufaturado & $-0,5$ & 10,9 & $-3,1$ & 7,3 \\
Manufaturado & 1,5 & 6,4 & $-2,6$ & 5,2 \\
\hline
\end{tabular}

(1) Ver classificação no Anexo 1.

Fonte de dados básicos: FAOSTAT.

A diferença quanto ao efeito quantidade é ainda mais nítida. No passado, o conjunto dos produtos básicos era o que apresentava menor

${ }^{5}$ Na pauta agrícola constaram 390 produtos sendo 117 classificados como básicos, responsáveis por $65,8 \%$ do valor exportado no triênio 2001-03. Foram classificados como semimanufaturados e manufaturados, respectivamente, 77 e 136 produtos que responderam por $10,1 \%$ e $24,1 \%$ do valor exportado no triênio. 
crescimento do volume exportado, $4,5 \%$ ao ano contra $13,4 \%$ ao ano dos semimanufaturados e $7,1 \%$ ao ano dos manufaturados. Entre os triênios 1996-98 e 2001-03, o crescimento da quantidade exportada dos básicos passou a 15,0\% ao ano, apesar da redução dos preços à taxa anual de $8,1 \%$ ao ano. Semimanufaturados e manufaturados também apresentaram declínio de preço e aumento da quantidade exportada, mas com menor ritmo de crescimento, resultando em redução do valor das exportações de manufaturados à taxa anual de 0,3\% e crescimento de 1,5\% ao ano para semimanufaturados. Já no caso dos produtos básicos, o crescimento foi de $5,3 \%$ ao ano. O confronto desses resultados indica que a desindustrialização aconteceu também dentro do agronegócio, e se deve ao aumento do volume exportado.

A preponderância do efeito quantidade sobre o valor das exportações agrícolas fica mais evidente quando é decomposto o valor das exportações expresso em moeda nacional. O cálculo foi feito tomando o índice mensal da taxa de câmbio real efetiva deflacionada pelo IPA-OG e calculando a média anual da taxa de câmbio ${ }^{6}$. Essa experiência é útil para analisar a influência do preço, descontado o impacto das variações reais do câmbio.

Entre os extremos da série houve desvalorização cambial de menos de $1 \%$, resultando em taxa anual de crescimento do valor das exportações em real $(7,2 \%)$ igual à obtida pelos cálculos em dólar. No entanto, a análise por sub-períodos apresenta divergências interessantes. Entre os triênios 1991-93 e 1996-98, por exemplo, a valorização cambial reduziu a taxa anual de crescimento das exportações de $11,2 \%$, quando o valor é expresso em dólar, para 6,7\% quando expresso em real. Essa redução se deveu à valorização cambial que neutralizou boa parte do crescimento dos preços internacionais das commodities agrícolas quando expresso em moeda nacional: de crescimento de 6,9\% ao ano em dólar, a taxa passou para 2,6\% ao ano em real (Tabelas 2 e 5).

Entre os triênios 1996-98 e 2001-03, apesar da depreciação real efetiva média de $23,7 \%$, a contribuição dos preços das commodities sobre

${ }^{6} \mathrm{O}$ índice da taxa de câmbio efetiva real, deflacionada pelo IPA-OG, apresentou média de 108,7 para o triênio 1991-93, de 88,7 para o triênio 1986-88 e 109,7 para 2001-2003. Isso significa que entre o início e o triênio 1986-88 a moeda nacional teve apreciação real de $18,4 \%$. Daí ao final, a série passou por depreciação de $23,7 \%$. A comparação dos extremos mostra variação real do câmbio de menos de $1 \%$ (IPEADATA, 2006). 
o valor exportado, em real, mostrou redução, à taxa anual de $-3,3 \%$ ao ano. Como o efeito da flexibilidade da pauta também apresentou resultado negativo ( $-1,1 \%$ ao ano), o que explica o consagrado sucesso da agricultura brasileira é o efeito quantidade, cujo crescimento se deu à taxa média anual de $12,2 \%$ ao ano (tabela 5).

Tabela 5. Componentes da Variação Média Anual do Valor das Exportações Agrícolas Brasileiras, medido em Real; Período: 1991 a 2003 (em porcentagem)

\begin{tabular}{cccccc}
\hline Inicial & Final & Preço & Quantidade & Flexibilidade & Total \\
\hline $1991-93$ & $1996-98$ & 2,6 & 6,0 & $-2,0$ & 6,7 \\
$1996-98$ & $2001-03$ & $-3,3$ & 12,2 & $-1,1$ & 7,8 \\
$1991-93$ & $2001-03$ & $-0,5$ & 9,0 & $-1,3$ & 7,2 \\
\hline
\end{tabular}

(1) Valor real deflacionado pelo IPA-OG

Fontes de dados básicos: FAOSTAT e IPEADATA

\section{Conclusões}

A liberalização comercial da década de 1990 modificou a estrutura produtiva do Brasil e resultou em crescimento mais acelerado dos produtos obtidos com o emprego mais intensivo de recursos naturais. Alavancada pelas exportações, a agricultura cresceu bem mais que o resto da economia e, por algum tempo, seu desempenho provocou reações entusiasmadas.

A continuidade do crescimento do setor acabou por gerar preocupações, notadamente pelos efeitos sobre a taxa de câmbio. A recente notoriedade das expressões doença holandesa e maldição dos recursos naturais no País, é resultado da extensão à realidade brasileira de conceitos antes aplicados às economias que enfrentaram desindustrialização resultante do crescimento acelerado das exportações de recursos naturais, particularmente de petróleo. Argumenta-se que aos superávits agrícolas se deve a apreciação da moeda doméstica, e esta, por sua vez, inibe as exportações de produtos que não refletem as tradicionais vantagens comparativas do país, resultando em desindustrialização. A partir desse encadeamento buscou-se explorar as causas do superávit agrícola no período 1991-2003. 
A análise permitiu concluir que para a fase anterior à mudança do regime cambial as exportações agrícolas do Brasil cresceram bem mais que seu potencial, fato explicado pelos ganhos em competitividade (3,3\% ao ano), que deve ser somado à melhoria da composição da pauta agrícola $(2,1 \%$ ao ano).

Na fase posterior, a expansão das exportações agrícolas também foi muito superior ao seu crescimento potencial, mas os ganhos de competitividade $(4,8 \%$ a.a.) foram parcialmente neutralizados pela mudança desfavorável na composição da pauta (-1,6\% a.a.). Essa mudança é considerada desfavorável porque implica aumento da vulnerabilidade do país, que aumentou sua participação no comércio de produtos que estão em declínio nas importações mundiais.

Os resultados mostraram também que os propalados ganhos de competitividade da agricultura brasileira são devidos, predominantemente, ao aumento da quantidade exportada. Antes da mudança do regime cambial os preços dividiam a responsabilidade pelo crescimento do valor das exportações, mas como a moeda brasileira estava sobre-valorizada, o câmbio anulava mais da metade dos ganhos para o produtor doméstico. Depois da desvalorização do câmbio, parte dos ganhos de competitividade foi neutralizada pela baixa dos preços internacionais dos produtos agrícolas exportados pelo Brasil. Mesmo levando em conta a desvalorização cambial do período, a contribuição dos preços na composição do valor das exportações foi negativa, ou seja, a desvalorização não foi suficiente para compensar a baixa dos preços internacionais.

Acrescente-se que em todo o período analisado a pauta agrícola brasileira mostrou grande participação de produtos em desacordo com a lei geral da oferta. É o que explica o efeito flexibilidade sempre negativo. Antes da mudança cambial, cerca de $1 / 4$ do valor das exportações procedia de produtos que o Brasil reduzia a quantidade exportada mesmo com preços em alta. No período posterior o quadro é bem mais grave: $88,1 \%$ das exportações provieram do aumento do volume exportado de produtos em baixa no mercado externo.

A conclusão geral é que os ganhos de competitividade da agricultura brasileira foram acompanhados por piora da qualidade dessas exportações. Esse fato é mais evidente depois da mudança do regime cambial, etapa em que o Brasil avançou em volume exportado, mas sua pauta 
agrícola foi dominada por produtos em declínio no mercado internacional. Como o valor das exportações de produtos manufaturados de origem agrícola diminuiu, enquanto cresceu o comércio de produtos básicos, pode-se concluir que o processo de desindustrialização vitimou também o agronegócio brasileiro, que passou a concentrar a exportação em produtos com menor valor agregado.

\section{Referências bibliográficas}

BARROS, L. C. M. A “doença brasileira”. Folha de S. Paulo, São Paulo, 23 set. 2005. Disponível em: < http://www1.folha.uol.com.br/fsp/ dinheiro/fi2309200508.htm > . Acesso em: 10 fev. 2006.

BRESSER-PEREIRA, Luiz C. Maldição dos recursos naturais. , São Paulo, 06 jun. 2005a. Disponível em: < http://www1.folha.uol.com.br/ fsp/dinheiro/ fi0606200505.htm > . Acesso em: 13 fev. 2006.

Desenvolvimento como estratégia nacional. São Paulo: FGV jul. 2005b. (Textos para discussão, 144).

FAJNZYLBER, F. Inserción internacional e innovación institucional. Revista de La Cepal, Santiago de Chile, n. 44, p. 149-178, Ago. 1991.

FAOSTAT database. Disponível em < http://faostat.fao.org/faostat/ form? collection $=$ Trade $>$. Acesso em: nov. 2005 .

GASQUES, J. G. et al. Desempenho e crescimento do agronegócio no Brasil. Brasília: IPEA, fev. 2004 (Texto para discussão, 1009).

IEDI. Ocorreu uma desindustrialização no Brasil? São Paulo, novembro de 2005. Disponível em: < http://www.iedi.org.br/cgi/cgilua.exe/sys/ start. htm? $s i d=77 \&$ UserActiveTemplate $=$ iedi\& infoid $=1685>$. Acesso em: 13 fev. 2006.

IPEADATA. Disponível em: < http://www.ipeadata.gov.br/ipeaweb. dll/ipeadata?262759484 > . Acesso em: fev. 2006.

NEVES, M. F. "A década do agronegócio". O Estado de S. Paulo, São Paulo, 16 jan. 2004. disponível em: < http://www.fundacaofia.com.br/ pensa/boletim/boletim07.htm > . Acesso em: 10 fev. 2006. 
PALMA, J. G. Quatro fontes de “desindustrialização” e um novo conceito de "doença holandesa". In: CONFERÊNCIA DE INDUSTRIALIZA ÇÃO,DESINDUSTRIALIZAÇÃO E DESENVOLVIMENTO ORGANIZADA, 2005, São Paulo. Anais eletrônicos... São Paulo: FIESP: IEDI, 2005. Disponível em: < http://www.fiesp.com.br/download/ publicacoes_economia/jose_gabriel_palma.pdf > . Acesso em: 09 fev. 2006.

PASTORE, A. C.; PINOTTI, M. C. Câmbio, reservas e "doença holandesa”. Valor Econômico, São Paulo, 30 jan. 2006. Disponível em: < http://www.observatorio. setrab.rj.gov. br/ I_CENTRAL/artigos/ artigo_300106.htm > . Acesso em: 10 fev. 2006.

PUGA, F. P. et al. O comércio Brasil-China: situação atual e potencialidades de crescimento. Rio de Janeiro: BNDES, 2005. (Texto para discussão, 104). Disponível em: < http://www.bndes.gov.br/conhecimento/ td/td-104.pdf > . Acesso em: 06 fev. 2006.

RICUPERO, R. A desindustrializaçao como projeto. Folha de S. Paulo, São Paulo, 02 out. 2005. Disponível em: < http://www1.folha.uol. com.br/fsp/dinheiro/fi0210200505.htm > . Acesso em: 10 fev. 2006.

SHAFAEDDIN, S. M. Trade liberalization and economic reform in developing countries: structural change or de-industrialization? UNCTAD, Apr. 2005. (Discussion papers, 179). Disponível em: < http://www. unctad.org/en/docs/osgdp20053_en.pdf > . Acesso em: 10 fev. 2006.

STIGLITZ, J. A maldição dos recursos naturais. Valor Econômico, São Paulo, 12 ago. 2004. Caderno A, p 12. Disponível em: < http://www. amazonia.org.br/ef/opiniao/print. $\operatorname{cfm} ? \mathrm{id}=119932>$. Acesso em: 09 fev. 2006. 
Anexo 1. Classificação dos Principais Produtos Agrícolas e Participação no Valor Exportado, Brasil, 1991 a 2003 (1) (em porcentagem)

\begin{tabular}{|c|c|c|c|c|c|c|}
\hline \multirow{2}{*}{ Ordem } & \multirow{2}{*}{ Tipo } & \multirow{2}{*}{ Item } & $1991-93$ & \multirow{2}{*}{$\frac{1991-93}{\text { acumulado }}$} & \multirow{2}{*}{$\begin{array}{l}\text { 2001-03 } \\
\text { simples }\end{array}$} & \multirow{2}{*}{$\frac{2001-03}{\text { acumulado }}$} \\
\hline & & & simples & & & \\
\hline 1 & Básico & Soybeans & 8,27 & 8,27 & 18,82 & 18,82 \\
\hline 2 & Básico & Cake of Soya Beans & 17,95 & 26,22 & 12,86 & 31,68 \\
\hline 3 & Básico & Chicken Meat & 5,22 & 31,44 & 8,12 & 39,80 \\
\hline 4 & Semimanufaturado & Sugar (Centrifugal, Raw) & 4,27 & 35,70 & 7,23 & 47,04 \\
\hline 5 & Básico & Coffee, Green & 12,83 & 48,53 & 6,94 & 53,98 \\
\hline 6 & Básico & Tobacco Leaves & 8,19 & 56,72 & 5,53 & 59,51 \\
\hline 7 & Básico & Beef and Veal,Boneless & 2,75 & 59,47 & 5,00 & 64,50 \\
\hline 8 & Manufaturado & Sugar Refined & 2,59 & 62,06 & 4,96 & 69,47 \\
\hline 9 & Manufaturado & Oranjuice Concentrated & 10,43 & 72,50 & 4,85 & 74,32 \\
\hline 10 & Manufaturado & Oil of Soya Beans & 3,07 & 75,57 & 4,71 & 79,03 \\
\hline 11 & Básico & Maize & 0,01 & 75,58 & 2,14 & 81,17 \\
\hline 12 & Básico & Pork & 0,00 & 75,58 & 1,72 & 82,89 \\
\hline 13 & Manufaturado & Beef Preparations & 3,04 & 78,61 & 1,67 & 84,56 \\
\hline 14 & Manufaturado & Coffee Extracts & 1,97 & 80,58 & 1,16 & 85,71 \\
\hline 15 & Manufaturado & Food Prepared nes & 0,30 & 80,88 & 1,13 & 86,85 \\
\hline 16 & Manufaturado & Oranjuice Single-Strengt & 0,01 & 80,89 & 0,91 & 87,76 \\
\hline 17 & Manufaturado & Cotton Lint & 0,68 & 81,57 & 0,82 & 88,58 \\
\hline 18 & Básico & Pigmeat & 0,69 & 82,25 & 0,79 & 89,37 \\
\hline 19 & Semimanufaturado & Cashew Nuts Shelled & 1,42 & 83,67 & 0,68 & 90,05 \\
\hline 20 & Básico & Turkey Meat & 0,29 & 83,96 & 0,67 & 90,72 \\
\hline 21 & Manufaturado & Sugar Confectionery & 0,72 & 84,68 & 0,65 & 91,37 \\
\hline 22 & Semimanufaturado & Chocolate Products nes & 0,44 & 85,12 & 0,47 & 91,84 \\
\hline 23 & Manufaturado & Essential Oils nes & 0,58 & 85,70 & 0,46 & 92,30 \\
\hline 24 & Semimanufaturado & Cocoa Butter & 1,30 & 86,99 & 0,42 & 92,72 \\
\hline 25 & Manufaturado & Meat Canned Chicken & 0,01 & 87,01 & 0,36 & 93,08 \\
\hline 26 & Semimanufaturado & Fruit Pulp for Feed & 1,24 & 88,25 & 0,35 & 93,43 \\
\hline 27 & Básico & Pepper,White/Long/Black & 0,38 & 88,64 & 0,33 & 93,76 \\
\hline 28 & Básico & Mangoes & 0,12 & 88,75 & 0,33 & 94,10 \\
\hline 29 & Semimanufaturado & Cocoa Powder and Cake & 0,24 & 88,99 & 0,29 & 94,39 \\
\hline 30 & Básico & Cantaloupes\&oth Melons & 0,24 & 89,23 & 0,25 & 94,64 \\
\hline 31 & Básico & Grapes & 0,11 & 89,34 & 0,22 & 94,86 \\
\hline 32 & Básico & Offals of Cattle, Edible & 0,20 & 89,53 & 0,19 & 95,05 \\
\hline 33 & Manufaturado & Pastry & 0,05 & 89,59 & 0,18 & 95,23 \\
\hline 34 & Semimanufaturado & Waxes Veg 431.43 & 0,36 & 89,95 & 0,17 & 95,39 \\
\hline 35 & Básico & Apples & 0,13 & 90,07 & 0,16 & 95,56 \\
\hline 36 & Manufaturado & Fruit Prepared nes & 0,52 & 90,59 & 0,15 & 95,71 \\
\hline 37 & Básico & Bananas & 0,19 & 90,78 & 0,15 & 95,86 \\
\hline 38 & Básico & Horsemeat & 0,15 & 90,94 & 0,14 & 95,99 \\
\hline 39 & Básico & Honey & 0,00 & 90,94 & 0,13 & 96,13 \\
\hline 40 & Básico & Papayas & 0,03 & 90,97 & 0,13 & 96,26 \\
\hline 41 & Básico & Mate & 0,35 & 91,32 & 0,12 & 96,38 \\
\hline 42 & Manufaturado & Tobacco Products nes & 0,10 & 91,42 & 0,12 & 96,50 \\
\hline
\end{tabular}

RER, Rio de Janeiro, vol. 46, no 01, p. 053-073, jan/mar 2008 - Impressa em abril 2008 


\begin{tabular}{|c|c|c|c|c|c|c|}
\hline 43 & Manufaturado & Oil of Cotton Seed & 0,24 & 91,66 & 0,11 & 96,61 \\
\hline 44 & Semimanufaturado & Cocoa Paste & 0,43 & 92,09 & 0,11 & 96,71 \\
\hline 45 & Semimanufaturado & Food Wastes & 0,10 & 92,18 & 0,10 & 96,81 \\
\hline 46 & Manufaturado & Whole Milk,Condensed & 0,01 & 92,19 & 0,09 & 96,91 \\
\hline 47 & Básico & Oranges & 0,22 & 92,41 & 0,09 & 97,00 \\
\hline 48 & Manufaturado & Oils Hydrogenated & 0,02 & 92,43 & 0,09 & 97,09 \\
\hline 49 & Manufaturado & Beverages Dist Alcoholic & 0,16 & 92,59 & 0,09 & 97,17 \\
\hline 50 & Manufaturado & Fruit Juice nes & 0,11 & 92,71 & 0,09 & 97,26 \\
\hline & Básico & Total & 61,0 & & 65,8 & \\
\hline & Semimanufaturado & Total & 10,1 & & 10,1 & \\
\hline & Manufaturado & Total & 29,0 & & 24,1 & \\
\hline
\end{tabular}

(1) Classificação feita pelos autores com base em FUNCEX e SECEX. Fonte de dados básicos: FAOSTAT. 